\title{
NÓS OS EDUCADORES QUE AMÁVAMOS TANTO A REVOLUÇÃO: Origens, desenvolvimento e crise do campo trabalho-educação no Brasil.
}

\author{
José Rodrigues \\ Ronaldo Rosas Reis
}

\section{RESUMO:}

O presente artigo aborda as origens, o desenvolvimento dos debates e também a crise do campo Trabalho-Educação, tal qual este se organiza principalmente no seio da Associação Nacional de Pós-Graduação e Pesquisa em Educação (ANPEd). A abordagem baseia-se fundamentalmente na apreciação da produção teórica do Grupo de Trabalho TrabalhoEducação (GTTE) da ANPEd, seja através de diversos estudos que se detiveram sobre esta produção, seja com base na experiência dos autores como membros deste grupo. Subsidiariamente, a abordagem se valerá do acúmulo dos seus autores como professores e orientadores na linha de pesquisa "O Mundo do Trabalho e a Formação Humana" do Programa de Pós-Graduação em Educação da Universidade Federal Fluminense. Portanto, serão infelizmente ignorados as inflexões e os debates presentes em outros setores da ANPEd.

Palavras-chave: Educação, Marxismo, Trabalho-Educação

\section{WE THE EDUCATORS WHO LOVED REVOLUTION Origins, development and crisis of the labor-education field in Brazil}

\section{ABSTRACT:}

This article addresses the origins, development discussions and also the crisis of the LaborEducation field, as this is organized mainly within the National Association of Graduated Studies and Research in Education (ANPEd). The approach is essentially based on appreciation of the theoretical proceedings of the ANPEd's Working Group LaborEducation (GTTE-09), either through various studies that have focused on this production, or based on the authors' experience as members of this group. Alternatively, the approach will stand on the buildup of its authors as teachers and mentors in the research venue "The world of work and human development" of the Graduate Program in Education at the Universidade Federal Fluminense. Therefore, the inflections and the present debates in other sectors of ANPEd will unfortunately be ignored.

Keywords: Education, Marxism, Labor-Education

\section{INTRODUÇÃO}

O socialismo comprometido com a democracia burguesa ainda é uma forma de reprodução do sistema capitalista de poder.

(Florestan Fernandes, 1995, p. 252).

O estudo completo sobre a presença do pensamento marxista em Educação, no Brasil, é uma tarefa de grande monta, ainda por ser realizada, em que pese os trabalhos já produzidos. Nesse sentido, o presente texto pretende apenas dar um breve panorama sobre uma parcela importante da produção acadêmica contemporânea na área de Educação, na qual o pensamento marxista teve e ainda tem um peso significante. 
Cabe explicitar que se poderia estudar a influência do marxismo na política educacional brasileira, nas obras de grandes educadores (tais como Paulo Freire, Florestan Fernandes ou Paschoal Lemme), nas experiências pedagógicas passadas e em curso $^{1}$, nos debates e nas propostas oriundas do movimento sindical, e ainda nas entidades representativas da classe trabalhadora em geral e naquelas que buscam representar os docentes $^{2}$. De forma análoga, poder-se-ia abordar a recepção e a penetração das ideias marxianas ao longo da história da educação através de rastreamento de determinados índices na bibliografia brasileira de educação. Enfim, como já foi dito, apresentar e analisar as relações entre o pensamento marxista e a educação brasileira é uma tarefa ainda por ser vencida.

Assim, consciente de suas limitações, o presente artigo aborda as origens, o desenvolvimento dos debates e também a crise do campo Trabalho-Educação, tal qual este se organiza principalmente no seio da Associação Nacional de Pós-Graduação e Pesquisa em Educação (ANPEd). A abordagem baseia-se fundamentalmente na apreciação da produção teórica do Grupo de Trabalho Trabalho-Educação (GTTE) da ANPEd, seja através de diversos estudos que se detiveram sobre esta produção ${ }^{3}$, seja com base na experiência dos autores como membros deste grupo $^{4}$. Portanto, serão infelizmente ignorados as inflexões e os debates presentes em outros setores da ANPEd, tais como os grupos de trabalho de História da Educação e de Política Educacional, grupos nos quais certamente - encontramos relevantes contribuições do pensamento marxista à educação. Subsidiariamente, a abordagem se valerá do acúmulo dos seus autores como professores e orientadores na linha de pesquisa "O Mundo do Trabalho e a Formação Humana", do campo de confluência Trabalho e Educação, do Programa de Pós-Graduação em Educação da Universidade Federal Fluminense.

O texto está organizado em quatro seções, além desta introdução. Primeiramente, será abordada, de maneira breve, a origem da pós-graduação em educação. Em seguida, precedido por uma abordagem contextualizada das esferas política e cultural nos anos de 1980, será apresentada a origem do pensamento marxista em educação, onde se destaca o papel de Dermeval Saviani, bem como a constituição, a tendência e a crise da área Trabalho-Educação. Na terceira seção, também de forma contextualizada, discutiremos o fim da hegemonia marxista no campo educacional, a partir da atual crise que se expressa tanto crise do marxismo nas Ciências Humanas quanto no cenário político mais amplo. Por último, a título de conclusão, apresentamos um apontamento subsidiário à reflexão do campo marxista.

\section{A PESQUISA E A PÓS-GRADUAÇÃO EM EDUCAÇÃO}

Há pelo menos 25 anos a produção acadêmica de professores das universidades públicas brasileiras, em sua grande maioria pesquisadores de programas de pós-graduação em educação, tem sido a principal fonte que alimenta, orienta e define o pensamento educacional brasileiro, embora não necessariamente a política pública de educação. Sem desconsiderar as marcas de grandes educadores como Paulo Freire na história da educação, de uma maneira geral pode-se afirmar que uma parcela significativa da segunda geração de pesquisadores acadêmicos profissionais formou-se sob a perspectiva marxista, particularmente de corte gramsciano, impulsionada por Dermeval Saviani, primeiramente na PUC-SP e, depois, na UNICAMP'.

A origem da pós-graduação em educação no Brasil remonta ao ano de 1965 quando vem a lume, de um lado, o Parecer n 977 do então Conselho Federal de Educação (CFE), 
e, de outro lado, com a instituição do Programa de Pós-Graduação em Educação, na Pontifícia Universidade Católica do Rio de Janeiro.

Com efeito, em 3 de dezembro de 1965, é exarado pela Câmara de Ensino Superior do CFE, o referido Parecer 977/65, cuja relatoria coube a Newton Sucupira, que definia a pós-graduação, sua finalidade, seus níveis e modalidades, inspirado em grande medida na experiência estadunidense que, por sua vez, havia sido fortemente influenciada pela universidade alemã.

Segundo Cury (2005, p.10), do ponto de vista doutrinário e oficial, no Brasil, esse parecer permanece sendo a única referência sistemática da pós-graduação. Sua efetivação se deu através da homologação do ministro da Educação, publicada no Diário Oficial, em 20 de janeiro de 1966.

Apoiado na então primeira Lei de Diretrizes e Bases da Educação Nacional (LDB, Lei 4.024/61), o Parecer indica que a pós-graduação, preferencialmente estabelecida na universidade, teria como objetivos a formação do corpo docente do ensino superior e de pesquisadores, assim como a formação de outros quadros técnico-administrativos necessários ao desenvolvimento nacional. Aliás, foi precisamente em torno do combate ao "atraso" (econômico, científico, tecnológico) que, de alguma forma, configurou-se uma aliança entre os professores universitários e o establishment político.

$\mathrm{Na}$ curta trajetória da pesquisa educacional podem ser distinguidos três períodos (GOUVEIA, 1971, apud FERRARO, 2006). O primeiro período tem seu marco inicial dado pela fundação, em 1938, do Instituto Nacional de Estudos Pedagógicos (INEP), pelo Ministério da Educação e Cultura (MEC), e nele predominaram estudos de natureza psicopedagógica. O segundo período, que se estende de 1956 a 1964, tem seu início marcado pela criação, por parte do próprio INEP, do Centro Brasileiro de Pesquisa Educacional e dos Centros Regionais de Pesquisa, incumbidos de desenvolver pesquisas com vistas à elaboração de uma política nacional de educação. Nesse segundo período predominaram os estudos de caráter sociológico. Finalmente, o terceiro período é inaugurado nos primeiros anos da Ditadura Militar estendendo-se até o início da década de 1970, no qual onde predominaram os estudos de natureza econômica.

Entre 1972 e 1978, houve um crescimento vertiginoso de programas de pósgraduação em educação (totalizando 25 cursos de mestrado e quatro de doutorados), que culminou com a criação da Associação Nacional de Pós-Graduação e Pesquisa em Educação (ANPEd), em grande medida incentivada pelo Governo Federal, particularmente pela Coordenação de Aperfeiçoamento de Pessoal de Nível Superior (CAPES). Contudo, contrariamente ao interesse governamental, a ANPEd, desde então, procurou congregar dois tipos de sócios: os institucionais, isto é, os programas de pós-graduação, e os individuais, ou seja, os pesquisadores em educação.

Em grande medida, essa dupla identidade da Associação representaria duas características, duas concepções, ora concorrentes, ora divergentes. Por um lado, a ANPEd teria o propósito de incentivar o desenvolvimento da pesquisa (e da crítica) em educação e, por outro lado, a de funcionar como formuladora de política educacional. Esta dupla identidade da Associação acabaria por criar tensões entre aqueles pesquisadores que ao estudarem a educação escolar brasileira passam a denunciar as orientações governamentais e aqueles que entendem que devem colocar seus saberes a serviço da "melhoria" da política de Estado para a educação. Grosso modo, os primeiros defendem a autonomia e a independência da entidade e da produção científica frente ao Estado, enquanto os segundos optam pela colaboração política e acadêmica - mesmo que eventualmente "crítica" - da ANPEd com os órgãos governamentais ${ }^{6}$. 
Nas palavras de Dermeval Saviani,

Embora implantada segundo o espírito do projeto militar do "Brasil Grande" e da modernização integradora do país ao capitalismo de mercado associado-dependente, a pós-graduação se constituiu num espaço privilegiado para o incremento da produção científica e, no caso, da educação, também para o desenvolvimento de uma tendência crítica que, embora não predominante, gerou estudos consistentes sobre cuja base foi possível formular a crítica e a denúncia sistemática da pedagogia dominante, alimentando um movimento de contraideologia (SAVIANI, 2005, p.37, apud CURY, 2005, p.19).

É precisamente nesse movimento contraideológico, não isento de contradições, conforme veremos mais adiante, que se inscreve o pensamento marxista em educação. Com efeito, a década de 1980 viu emergir, no cenário educacional, as pedagogias contrahegemônicas: "pedagogias da educação popular", "pedagogias da prática", "pedagogia crítico-social dos conteúdos" e "pedagogia histórico-crítica" (cf. SAVIANI, 2007a, cap.XIII). Nesse sentido, como já foi mencionado, embora o GT Trabalho e Educação não congregue a totalidade de pesquisadores em educação que se pautam pelo marxismo, sem dúvida, é neste grupo de trabalho da ANPEd que ainda se dão os principais debates em torno do materialismo histórico como ferramenta de compreensão e transformação da realidade educacional brasileira.

\section{O PENSAMENTO MARXISTA EM EDUCAÇÃO: ORIGENS, PERCURSO E CRISE DO GTTE}

\section{CONTEXTO}

A década de 1980, no Brasil, é considerada por muitos como a "década perdida", dada a perversa combinação de estagnação econômica com altas taxas de inflação denominada de estagflação. E não poderia ser diferente, pois, na condição histórica de país dependente e desigual, o Brasil passaria a experimentar internamente os efeitos da crise mundial dos anos de 1970 e os efeitos de duas décadas de ditadura militar.

De fato, na esfera política mais ampla o país viveu "à flor da pele", experimentando intensamente a vitalidade característica do paroxismo que reúne no mesmo campo semântico a luta e o luto de tensões de todos os tipos: no Congresso e nas ruas, políticos de esquerda e centro-esquerda e a sociedade pressionavam os militares e o governo pela anistia ampla, geral e irrestrita, pelo retorno dos exilados, pelas "Diretas, já!"; nos bastidores, políticos reacionários e empresários conservadores urdiam acordos a fim de prolongarem ao máximo a chamada "transição democrática". Como resultado, a despeito do clima de heroica euforia e confraternização que tomara conta das pessoas que aos milhões foram às ruas pressionar os congressistas a votarem favoravelmente a emenda pelas eleições diretas, uma conjuração contra o povo brasileiro encabeçada pelo então governador mineiro Tancredo Neves acabaria prevalecendo no Congresso Nacional: a emenda constitucional Dante de Oliveira foi recusada por uma minoria de parlamentares, lançando o luto sobre aquele que foi certamente o mais significativo movimento de massa organizado pela sociedade civil brasileira, no século XX. Meses depois, eleito presidente do país pelos seus pares no parlamento, Tancredo não poderia assumir o cargo por se 
encontrar gravemente enfermo. Já tendo escolhido antecipadamente os membros do seu ministério e sua liderança no Congresso Nacional, Tancredo legaria ao presidente do Congresso Nacional, o deputado Ulysses Guimarães, a tarefa de decidir sobre qual dos caminhos o país deveria seguir diante da encruzilhada para o qual ele o havia levado com todas as suas articulações de bastidores. Como opções Ulysses tinha a decidir entre seguir o rito constitucional e realizar uma nova eleição indireta, assumir ele próprio o comando da nação ou dar posse ao vice-presidente de Tancredo Neves, no caso o então deputado José Sarney. Ocorre que sobre este último pairavam as mais legítimas desconfianças dos movimentos populares organizados, dos sindicalistas e, de um modo geral, da população. De fato, José Sarney era um dos principais articuladores do apoio aos militares no Congresso Nacional. Fora ele um dos articuladores de primeira hora do golpe militar no Maranhão, onde logrou construir um sólido patrimônio financeiro e político com a proteção do regime ditatorial. No episódio da votação da emenda Dante de Oliveira, Sarney fora o responsável direto pela sua derrota no Congresso Nacional, contudo, logo em seguida, se sentiria traído pelo general-presidente Figueiredo quando este optou por apoiar a candidatura do então governador de São Paulo, Paulo Maluf, para concorrer à presidência da república no Colégio Eleitoral em janeiro de 1985. Juntando-se a outros políticos situacionistas igualmente insatisfeitos, Sarney ajudaria a fundar a Frente Liberal, mais tarde - Partido da Frente Liberal (PFL, atual DEM) -, e daí em diante jogaria todo o seu apoio à candidatura de Tancredo Neves, tornando-se por isso o seu companheiro de chapa como candidato à vice-presidente.

Ainda assim, sob os mais variados tipos de pressão, Ulysses Guimarães garantiria a posse interina do vice Sarney até que a situação de Tancredo Neves se definisse. Dessa forma, no dia 15 de março de 1985, José Sarney assumiria a presidência da República.

$\mathrm{Na}$ esfera cultural despontaria com força a retórica pós-moderna do show business induzindo uma parcela significativa de artistas e intelectuais burgueses de esquerda - a exemplo do que ocorrera na Europa e nos EUA - a repensar posições e ao esforço sistemático de deslegitimação do discurso de esquerda. De fato, em 1991, recapitulando a trajetória desse esforço uma década antes nos principais países capitalistas dos dois continentes, Fredric Jameson defendia a tese de que

[...] a retórica do mercado tem sido o componente central e fundamental da luta ideológica pela legitimação ou deslegitimação do discurso de esquerda. A capitulação diante das várias formas de ideologia do mercado - por parte da esquerda, quero dizer, deixando de lado todos os outros tem sido imperceptível, mas alarmantemente universal (1996, p.271).

Mas essa questão não resume toda a situação, de resto delicada para a atuação dos marxistas. Isto é, ao lado da retórica do mercado, no âmbito mesmo dos embates de esquerda, pensadores importantes como Michel Foucault, por exemplo, passaram a alimentar direta ou indiretamente os impulsos antiintelectual e anticlassista de uma geração de intelectuais em formação, cujas consequências mais impactantes foram, sem dúvida, a apologia do "nada" como filosofia existencial e o apoio ideológico dado ao "decreto do fim da história”, elaborado por Francis Fukuyama7. Como ressalta Jameson (1996), sob o pósmodernismo, o capitalismo não apenas aburguesou o trabalhador travestindo-o num consumidor conspícuo buscando desconstruir os conceitos de classe e de luta de classes como tornou mais evidentes a necessidade imperiosa de cooptação da intelectualidade à ideia da "prática pela prática", promovendo, como será retomado na seção seguinte, um 
"alívio" ou "desbloqueio", ou ainda "liberação" de toda e qualquer atitude calcada naquilo que se entendia então como "racionalidade moderna" (idem, pp. 317-319).

Retomando o contexto na perspectiva histórica que aqui se apresentava, é de se notar que, ao final da década de 1970, os temas da pós-modernidade mais serviram para amplificar e acelerar uma divisão da intelectualidade brasileira cujo acúmulo remontava a pelo menos três décadas de tensões e embates vividos na área cultural em torno de conceitos e posturas ideológicas. Ora, sendo verdade que a manu militari que se abatera pesadamente sobre a sociedade servira apenas para unir artificialmente uma intelectualidade burguesa de esquerda ideologicamente dependente e desigual como o país, não menos certo será também considerar que o lento e tímido processo de abertura política teria muito a dizer sobre as limitações de base de grande parte da intelectualidade brasileira ${ }^{8}$.

De fato, formada precariamente em pouco mais de quarenta anos de fundação das primeiras universidades, frequentemente cooptada pelo Estado e pela classe burguesa sob pretextos diversos, legítimos ou não (estratégia, tática, compadrios etc.), a base epistemológica e metodológica da grande maioria dos intelectuais em fins dos anos de 1970 e início dos anos de 1980 carecia (e, como veremos adiante, parece ainda carecer) fundamentalmente da práxis como afirmação do ser livre, criativo e revolucionário.

Dessa maneira com a mesma intensidade com que as posições deslegitimadoras do discurso da Totalidade empurravam para longe do ambiente cultural brasileiro o debate sobre a luta de classes e todos os temas a ela relacionados, os temas da diversidade e o da problemática ética e estética em torno do esgotamento da racionalidade e da utopia, ganhavam espaço na agenda política dos debates e das produções artísticas da década de 1980. Em meados daquela década já era possível observar muitos daqueles que "amavam tanto a revolução" realizarem uma inflexão em direção ao vazio pós-moderno?.

\section{A EDUCAÇÃO FAZ A DIFERENÇA}

Os estudos de esquerda sobre o tema cultura e sociedade estão ainda a dever uma explicação acerca dos motivos pelos quais o campo educacional tem sido abordado de forma marginal no ambiente cultural brasileiro. Um dos aspectos interessantes que poderia ser esclarecido, por exemplo, refere-se ao motivo pelos qual, na década de 1980, o campo educacional caminhou na contramão da tendência ao enfraquecimento da luta social e à flexibilização ideológica observada nas artes, no teatro, no cinema e na literatura, fazendo dela palco de intensa mobilização, organização e luta do campo educacional.

Com efeito, em 1981, foi fundada a Associação Nacional de Docentes do Ensino Superior (ANDES) ${ }^{10}$, já em 1989, a antiga Confederação de Professores do Brasil (CPB) é transformada substancialmente convertendo-se na Confederação Nacional dos Trabalhadores da Educação (CNTE). Entidades que assumiam seu papel de luta contrahegemônica inclusive filiando-se à Central Única dos Trabalhadores (CUT).

Além das entidades de caráter sindical, diversas entidades de caráter científico foram fundadas e desenvolveram importantes ações. Dentre essas talvez possamos destacar a Associação Nacional de Educação (ANDE) e o Centro de Estudos Educação e Sociedade (CEDES). Essas entidades em associação com a ANPEd organizaram as Conferências Brasileiras de Educação (CBEs) $)^{11}$ que tiveram enorme papel na mobilização, organização e luta dos educadores contra a política educação implementada pela Ditadura Militar. Nas palavras de Saviani: 
nova fase da educação brasileira. Preocupada com novas propostas pedagógicas, essa fase abriu espaço para a emergência de concepções contra-hegemônicas (SAVIANI, 2007a, p.403).

Ao lado da intensa mobilização dos educadores contra a política educacional do governo federal, houve inúmeras iniciativas municipais e estaduais implantadas por prefeituras e governos estaduais "de oposição", isto é, de oposição ao governo federal empalmado pelos generais-presidentes.

Portanto, era de se esperar que o avanço da organização da luta dos educadores, apoiada em intensa produção intelectual, coadunada com políticas locais (municipais e estaduais) em oposição à política nacional de educação teria resultado na derrota (ou pelo menos, refluxo) desta última. Infelizmente, não foi isso o que efetivamente ocorreu: a política educacional nacional seguiu o seu curso - guiada pela concepção pedagógica tecnicista $^{12}-\mathrm{e}$ as experiências locais mostraram-se efêmeras e frustrantes.

De qualquer forma, a década de 1980 foi palco de significativo crescimento da produção acadêmica educacional - em geral, proveniente dos programas de pós-graduação em educação. Essa produção foi divulgada por muitas revistas especializadas, inúmeros livros e séries dedicadas à educação, nas grandes editoras, e até mesmo a constituição de editoras especializadas na temática educacional. Pelo vigoroso crescimento, o campo educacional foi reconhecido como tal pela comunidade científica, o que pode ser ilustrado pelo aumento do financiamento por parte das agências de fomento (nacionais e estaduais), assim como pela constituição de comitês específicos nestas. Tal contexto de intenso crescimento acadêmico, adensamento teórico e grande mobilização política, propiciaram a emergência de "propostas pedagógicas contra-hegemônicas" ou "pedagogias de esquerda" sendo que nem todas, necessariamente, de cariz marxista ou revolucionário (SAVIANI, 2007a, p.411) $)^{13}$.

As "pedagogias da educação popular", em grande medida, foram formuladas e difundidas por Paulo Freire, estando bastante próximas à Igreja Católica (afinada com a teologia da libertação) e, em seguida, à fração majoritária do Partido dos Trabalhadores. As "pedagogias da prática" também não podem ser definidas como marxistas posto que se guiaram preferencialmente pela tradição libertária, isto é, anarquista.

Diferentemente das anteriores, todas situadas no campo das concepções contrahegemônicas, a "pedagogia crítico-social dos conteúdos" - segundo expressão de José Carlos Libâneo - e a "pedagogia histórico-crítica" - cujo "manifesto de lançamento" é precisamente a obra Escola e Democracia de Saviani ${ }^{14}$ - são assumidamente inspiradas pelo marxismo ${ }^{15}$.

Segundo a própria síntese de Dermeval Saviani:

[...] pode-se considerar que a pedagogia histórico-crítica é tributária da concepção dialética, especificamente na versão do materialismo histórico, tendo fortes afinidades, no que se refere às bases psicológicas, com a psicologia histórico-cultural desenvolvida pela Escola de Vigotski (2007a, p. 419).

Nesse sentido, prossegue o autor: 


\begin{abstract}
A educação é entendida como o ato de produzir, direta e intencionalmente, em cada indivíduo singular, a humanidade que é produzida histórica e coletivamente pelo conjunto dos homens. Em outros termos, isso significa que a educação é entendida como mediação no seio da prática social global (Idem, p.420. Grifo nossos.).
\end{abstract}

Além da perspectiva que a educação é uma mediação, Saviani - ao lado de Manacorda - irá entender que o trabalho é o princípio educativo que, portanto, guia - ora explícita, ora implicitamente - a organização e o currículo escolares (SAVIANI, 2003c, p.133). A partir desses elementos, Saviani explicita concretamente o caráter de mediação da educação:

$\mathrm{Na}$ sociedade capitalista, a ciência é incorporada ao trabalho produtivo, convertendo-se em potência material. O conhecimento se converte em força produtiva e, portanto, em meio de produção. Assim, a contradição do capitalismo atravessa também a questão relativa ao conhecimento: se essa sociedade é baseada na propriedade privada dos meios de produção e se a ciência, como conhecimento, é um meio de produção, deveria ser propriedade privada da classe dominante. No entanto, os trabalhadores não podem ser expropriados de forma absoluta dos conhecimentos, porque, sem conhecimento, eles não podem produzir e, se eles não trabalham, não acrescentam valor ao capital. Desse modo, a sociedade capitalista desenvolveu mecanismos através dos quais procura expropriar o conhecimento dos trabalhadores e sistematizar, elaborar esses conhecimentos, e devolvê-los na forma parcelada (Idem, ibidem, p.137).

Grosso modo, portanto, a concepção pedagógica histórico-crítica pretende contribuir para traduzir - no plano especificamente educacional - a tese marxista de socialização dos meios de produção.

\title{
ORIGEM E PERCURSO
}

A partir da obra teórica e do ensino de Dermeval Saviani, constitui-se um grupo de pesquisadores que, com distinções internas, deram prosseguimento ao pensamento marxista em educação. Este grupo teve (e ainda tem) papel decisivo na constituição, no seio da ANPEd, do Grupo de Trabalho Trabalho-Educação.

Com efeito, em 1981, na Reunião Anual da ANPEd, foi instituído o GT Educação e Trabalho. Naquele contexto, podem ser destacadas as participações de Gaudêncio Frigotto, Acácia Kuenzer e Lucília Machado, cujas obras (teses doutorais publicadas) podem também ser consideradas como fundadoras do campo Trabalho-Educação.

De forma bastante sintética, até aquele momento, Frigotto se notabilizara pela pesquisa sobre as práticas pedagógicas de formação profissional do SENAI - publicada sob o título Fazendo pelas mãos a cabeça do trabalhador (FRIGOTTO, 1983), além de A produtividade da escola improdutiva (FRIGOTTO, 1984), tese orientada por Saviani, PUC-SP. Esta última vem a ser a mais densa crítica marxista à teoria do capital humano e às visões que vinculam ou desvinculam linearmente a escola ao mundo do trabalho. Acácia 
Kuenzer, por sua vez, também orientada por Saviani, publicou sua tese intitulada A pedagogia da fábrica (KUENZER, 1985) - uma crítica teórica às práticas produtivopedagógicas aplicadas no universo fabril desenvolvida a partir do estudo de caso de uma moderna montadora de veículos, instalada no Paraná. Finalmente, Lucília Machado desenvolveu denso estudo de caráter histórico sobre as constituições dos sistemas públicos de educação, seja na perspectiva liberal, seja aqueles erigidos nos países do chamado socialismo real. Orientada por Carlos Jamil Cury (que por sua vez havia sido orientado por Saviani), Machado teve sua tese publicada sob o título Politecnia, escola unitária e trabalho (MACHADO, 1989).

Em 1986, após densa discussão teórica ocorrida numa reunião dos pesquisadores do então GT de Educação e Trabalho, é feita a opção pela inversão dos termos da denominação original do GT para Trabalho-Educação. Sinteticamente, a discussão confluiu para a compreensão de que as práticas educativas são de caráter secundário frente à primazia do trabalho. Em outras palavras, ao reconhecerem a concepção de que o trabalho é o princípio educativo por excelência, os pesquisadores não apenas tornavam pública a posição teórica marxista do GT, como também, ao que parece, buscariam doravante prescrever o método da crítica da economia política como diretriz para a construção do conhecimento sobre "[...] os processos pedagógicos escolares e nãoescolares a partir do mundo do trabalho" (KUENZER, 2001, p.55) ${ }^{16}$.

A tabela 1, abaixo, explicita o que foi dito até agora: o GTTE pode ser considerado um espaço do pensamento marxista em educação, com forte influência de seus fundadores, além das contribuições de A. Gramsci.

Tabela 1

Autores-referência do GTTE Anped (1998-2004)

\begin{tabular}{lc}
\hline Autor citado & $\begin{array}{c}\text { Média \% (aproximada) } \\
\text { dos trabalhos que citam }\end{array}$ \\
Marx & 35 \\
G. Frigotto & 26 \\
L. Machado & 22 \\
A. Kuenzer & 18 \\
Gramsci & 12 \\
\hline
\end{tabular}

Fonte: Anped. Adaptada de BONFIM (2006. p.20)

Percorrendo-se, ao longo dos anos a produção acadêmica do GT TrabalhoEducação da ANPEd, podem ser destacados os seguintes temas e tendências ${ }^{17}$ :

1. Trabalho e educação - teoria e história: o trabalho como princípio educativo; a evolução histórica do conceito de trabalho; a relação trabalho e educação e sua reconstrução histórica.

2. Trabalho e educação básica: o trabalho e a continuidade/descontinuidade da escolarização do trabalhador; o mundo do trabalho, a escola e a formação científicotecnológica do trabalhador.

3. Profissionalização e trabalho: análise histórica das políticas de profissionalização definidas pelo Estado; trabalho, conhecimento e cidadania para a emancipação do trabalhador.

4. Educação do trabalhador nas relações sociais de produção: reestruturação produtiva, apropriação do conhecimento nos processos produtivos; a organização da produção e suas propostas pedagógicas; a escola, o trabalho, a sociedade e a construção da hegemonia.

5. Trabalho e educação nos movimentos sociais: a construção de identidades de diferentes categorias de trabalhadores; demandas de conhecimentos científico- 
tecnológicos dos movimentos sociais com base na produção; a ação pedagógica nas formas cooperativas de organização dos trabalhadores.

Também de uma maneira bastante esquemática, a discussão teórica interna ao GTTE seguiu o seguinte percurso:

Primeiramente, o grupo foi se constituindo a partir da crítica da economia política da educação na sociedade burguesa. Como apontado mais acima, as contribuições de Frigotto, Kuenzer e Machado foram decisivas.

Em seguida, o grupo dedicou-se a uma a discussão sobre os fundamentos (marxistas) do próprio campo. Esta discussão redundou na inversão dos termos da denominação: de Educação e Trabalho para Trabalho-Educação.

A partir daí, os trabalhos apresentados nas reuniões anuais da ANPEd passaram a se concentrar em estudos sobre a reestruturação produtiva, seus impactos sobre a formação profissional e seus reflexos na educação escolar ${ }^{18}$. Em nossa avaliação, este momento foi marcado pela "sedução da reestruturação produtiva", posto que a discussão foi marcada por uma certa sociologia do trabalho de cariz descritivo e por vezes adaptativo.

Esse momento acabou estabelecendo implicitamente uma discussão no grupo. Seria possível que as inovações tecnológicas estariam demandando uma formação profissional de qualidade superior ao perfil estabelecido pelo taylorismo-fordismo? Ora, se a resposta fosse afirmativa, e assim a maioria parecia acreditar, então a escola e o saber escolar passariam a ser valorizados - finalmente - pela burguesia, nesta nova etapa do capitalismo. Com isso, muitos acreditaram que se poderia "trabalhar na contradição", isto é, construir uma política educacional e uma prática pedagógica que - apoiando-se nas demandas dos novos processos de trabalho - contribuiriam para a luta contra-hegemônica - curiosamente - em aliança com a fração da burguesia interna industrial.

Não por acaso, na mesma época, teses análogas levaram os sindicatos a aderirem à política governamental de "geração de emprego e renda" através da promoção de cursos rápidos de qualificação profissional. Em outras palavras, os sindicatos aderiram à concepção produtivista de educação ao promoverem (ou terceirizarem) cursos financiados pelo Fundo de Amparo ao Trabalhador (FAT). Com isso, objetivamente endossava-se a tese de que o desemprego é fruto da falta de escolaridade adequada (em quantidade e em qualidade $)^{19}$, posta desde a década de 1950 pela teoria do capital humano ${ }^{20}$. Em outras palavras, apostava-se numa suposta adequação crítico-funcional da educação às demandas do processo de trabalho capitalista.

De uma maneira geral, estas perspectivas, no GTTE e no movimento sindical, foram predominantes durante o governo Fernando Henrique Cardoso. Contudo, o discurso crítico geral ao neoliberalismo e à política educacional de Cardoso, notadamente no que tange reestruturação da educação profissional, acabou por dificultar uma maior adesão dos pesquisadores do campo à concepção pedagógica produtivista. Ora, esta interpretação revela-se correta a partir da posse de Lula da Silva na presidência da república.

Com efeito, de forma análoga ao movimento observado durante a chamada "transição democrática" - quando setores reformistas (quiçá social-democratas) identificados com o PCB assumiram postos no aparelho de Estado, tanto nos governos estaduais quanto no governo federal -, no governo Lula da Silva, diversos pesquisadores identificados como marxistas, inclusive membros ilustres do GT Trabalho-Educação, passaram a formular e a gerenciar a política educacional federal, especificamente a política de educação profissional ${ }^{21}$. 


\section{A CRISE DO GTTE}

Observado de longe e de fora da área educacional o movimento dos educadores e pesquisadores em educação caminhou resolutamente, na década de 1980, no sentido contrário do conservadorismo (em alguns casos reacionarismo) que se abateu sobre a grande maioria das demais áreas de conhecimento do país e mesmo do exterior ${ }^{22}$. Nesse sentido, o cenário educacional brasileiro foi palco de um forte debate, em cujo centro encontrava-se em disputa a reestruturação do sistema educacional brasileiro erigido durante o regime autoritário, instaurado pelo Golpe Militar, em 1964. Toda a cena política brasileira, inclusive o campo educacional, passava por um processo catártico de repensar profundamente o seu passado recente e de instaurar, a partir daí, as novas bases para a reconstrução da cidadania usurpada e reprimida. Naquele contexto histórico, precisamente em dezembro de 1987, o trabalho de Saviani tornou-se, sem dúvida, um marco no debate brasileiro da área trabalho-educação, em particular sobre as relações entre o ensino médio e o ensino técnico ${ }^{23}$.

A partir desse marco, muitos debates e diversas publicações foram produzidos com o fito de buscar novos rumos para a educação brasileira, especialmente para a superação (ou, pelo menos, o enfrentamento) da dualidade estrutural que historicamente marca as concepções e práticas educativas no Brasil.

Embora nunca tenha se encerrado, o debate sobre a relação entre ensino médio e técnico - visto pela ótica da politecnia - ficou relativamente restrito a poucos interessados, mesmo após a promulgação do decreto $n^{\circ}$ 2.208/97, que instituiu a chamada Reforma da Educação Profissional, ainda no primeiro governo Fernando Henrique Cardoso (19951998). Finalmente, o debate sobre a concepção de politecnia pareceu reavivar-se a partir do decreto sobre a educação profissional $n^{\circ} 5.154 / 04$, promulgado no governo Lula, em julho de $2004^{24}$.

A partir daí, grosso modo, dois grupos (ambos representados no GTTE) se posicionaram em torno da avaliação deste decreto. De um lado, aqueles que entenderam ser o decreto presidencial o único caminho possível em direção ao enfrentamento da dualidade educação profissional versus ensino médio ${ }^{25}$. De outro lado, alguns percebem que o decreto, pretendendo ser "realista", acaba por naturalizar e, até mesmo, aprofundar a dualidade $^{26}$. Curiosamente, ambos os grupos reivindicam-se partidários da concepção de educação politécnica (isto é, marxista) e contrários à dualidade educacional, considerada milenar e fruto da luta de classes.

Passados seis anos deste ponto de inflexão - posse de Lula e o seu decreto da educação profissional ${ }^{27}$-, a polarização só aumentou no campo Trabalho-Educação. De um lado, a maioria dos participantes do grupo, em que pesem suas posições políticas frente ao (e no) governo Lula da Silva, reafirma seu referencial teórico-metodológico como marxista. De outro lado, parafraseando Saviani (2007a, p. 413), os debates travados no seio das reuniões anuais revelam que uma parte dos pesquisadores do GTTE retoma (ou toma) a referência da visão liberal, "interpretando o marxismo apenas pelo ângulo da crítica às desigualdades sociais e da busca de igualdade de acesso e permanência nas escolas organizadas com o mesmo padrão de qualidade", tal qual transcorrera durante a "transição democrática".

\section{O FIM DA HEGEMONIA MARXISTA NO CAMPO EDUCACIONAL}

A partir de meados da década de 1990, de forma combinada e desigual com a chamada crise do marxismo, cuja face mais visível foi a "queda do muro", a produção acadêmica vem sofrendo um giro significativo de orientação temática e de perspectiva 
teórico-metodológica. Temas educacionais ligados à economia política da educação, à relação trabalho-educação, à política educacional, todos eles de caráter mais amplo (que trabalham com a categoria da totalidade), são paulatinamente colocados em segundo plano - quando não abandonados - cedendo lugar para a onda temática conhecida como "cotidiano escolar" 28 .

Por conseguinte, pensadores como Karl Marx e Antonio Gramsci, dentre outros autores marxistas, são substituídos por autores como Edgard Morin, Michel de Certeau, Michel Foucault e, mais recentemente, Boaventura de Souza Santos, cujas idéias assumem ser necessário uma "multiplicidade e fluidez" do pensamento dentro da qual se entende o "espaço/tempo do conhecimento criado no cotidiano como insubstituível no que se refere, sobretudo, aos conhecimentos da prática" (ALVES e GARCIA, 1999, p.13).

Para os marxistas nunca foi difícil admitir que as idéias libertárias de Paulo Freire tenham contribuído decisivamente para uma importante virada para a esquerda nas concepções pedagógicas de uma grande parcela dos educadores brasileiros a partir dos anos de 1970. O problema que se colocou para os educadores marxistas daí em diante foi saber resistir às investidas especulativas do hibridismo pedagógico que se seguiu ao avanço da grande onda freiriana, a partir da década de 1990. Pode-se dizer, em linhas gerais, que essa resistência faz parte da própria história do marxismo, tendo sido o próprio Marx em vida alvo de investidas semelhantes.

De fato, ao proceder à análise do estatuto ontológico do pensamento de Marx, o filósofo José Chasin (2009) chama a atenção para diversos problemas dessa ordem. Ao fazer referência, por exemplo, aos esforços "naturalistas e grosseiros" (p. 31) de Kautsky para amalgamar os pensamentos de Marx aos de Schiller, Goethe, Kant, Fitche e Hegel, o filósofo pergunta-se se é possível "engendrar algum tipo de discurso de rigor [...] mesmo se redutível ao método, com porções de uma ciência vazada em termos empiristas ainda abstratos, para a qual a história é uma 'coleção de fatos mortos' [...]" (p. 39). Para reforçar a sua negativa aos esforços de fusão, Chasin reporta-se a uma resposta dada por Marx na qual ele concluía que:

[...] quanto mais perfeito seja o entendimento político, tanto mais se acreditará na onipotência da vontade, e tanto mais resistirá a ver barreiras naturais e espirituais que se levantam diante dela, e mais incapaz será, por conseguinte, de descobrir a fonte dos males sociais (MARX, Escritos de Juventude apud CHASIN, idem, idem. Grifos do autor)

Ora, a evidente atualidade desse escrito marxiano seria suficiente para inscrevê-lo dentre as possíveis negativas às idéias pedagógicas engendradas a partir de e/ou diretamente pela "mão de Boaventura", nos últimos vinte anos, posto está que a sua proposta de um "conhecimento sem teoria" não apenas retoma o caráter especulativo do conhecimento meramente empiricista como ainda visa, estrategicamente, positivar o cotidiano escolar como o seu principal elemento de referência da chamada "educação popular". A partir desse ponto, entendemos ser necessário retomar a problemática dos discursos antiintelectualista e anticlassista deixado em aberto mais acima.

\section{RETORNO AO MESMO}

A reorientação temática assim como suas referências teórico-metodológicas, celebrada pelos pós-modernistas como a redenção da subjetividade do jugo da tirania da Razão Moderna, tem sido apenas a ponta de uma disputa política mais ampla e de consequências mais drásticas para o campo marxista. Ou seja, de acordo com Stanley 
Aronowitz (1990), no plano político, boa parte dos intelectuais celebradores do pósmodernismo considera essencial que a disputa pela causa democrática a ser travada na atualidade deve ter como premissa o combate teórico à totalidade. Trata-se, enfim, conforme sublinhado na seção anterior, do esforço pós-modernista de desconstrução dos conceitos de classe e de luta de classes em associação com a idéia de se promover o "alívio" ou o "desbloqueio", ou ainda a "liberação" de toda e qualquer atitude calcada na "racionalidade moderna".

Do ponto de vista ideológico mais amplo e mais profundo, referenciados nos pósestruturalistas franceses - Derrida e Foucault, especialmente -, uma impressionante quantidade de intelectuais, há um quarto de século têm procurado desconstruir o conceito de classe denunciando e combatendo aquilo que denominam de "discursos ideológicos totalizantes", em especial aqueles oriundos da fenomenologia hegeliana e principalmente os da crítica da economia política marxiana. Para os pós-modernistas tais discursos teriam sido responsáveis pelo surgimento no século XX de distopias totalitárias e excludentes, como o nazismo e o stalinismo, e nesse sentido seria necessário, portanto, pensar as relações entre as pessoas a partir de uma teia ou rede por onde circulam as práticas sociais como o poder, a violência, a corrupção, a segregação etc. Desse ponto de vista, denominado por Foucault como "microfísica", isto é, o poder é uma produção subjetiva como as demais mencionadas - que "transita pelo corpo dos indivíduos e os forma" sem que isso signifique que ele exista a partir de um centro "e pretender caracterizá-lo no movimento de sua irradiação". Essa parcela da intelectualidade acredita ser possível o aparecimento fortuito de uma neodemocracia fundada na "prática pela prática" ${ }^{29}$, desdenhando o fato concreto de que a base epistemológica sobre a qual apoiam a sua quase mística crença "libertária" no fim da história e das classes sociais, e na emergência de um sujeito indeterminado e radicalmente singular em verdade conforma dialeticamente uma negatividade patológica: qual seja a de reproduzir/retornar ao Mesmo.

Por conseguinte, na medida em que o percurso da razão científica ao longo do processo de apreensão e compreensão da realidade estabelece sínteses totalizantes, que nada mais são do que "narrativas mestras" ou "metanarrativas" do próprio método expositivo, fica bastante evidente o antagonismo entre este modo de pensar e a ideologia do pós-moderno.

Com efeito, para um pós-modernista, a racionalidade científica que por um longo tempo demarcou simbolicamente o espaço do que se compreende culturalmente como "modernidade", impôs ao pensamento dos séculos XIX e XX uma espécie de hierarquia epistemológica da realidade apreendida, devendo ser combatida em todas as frentes. Nesse sentido, a principal estratégia de combate dos ideólogos do pós-modernismo tem consistido no ataque as metanarrativas que marcaram as diversas formas de pensamento baseadas naquela racionalidade científica. Sustentam assim, uma ideologia equalizadora das produções humanas, na qual qualquer manifestação cultural, seja ela científica, metafísica ou afetiva, possui poder explicativo e valor social idênticos. Enfim, há o deslocamento da verdade para a subjetividade, para o "ponto de vista", para as inúmeras e diferentes interpretações do real, aliás, deste ponto de vista, a própria realidade seria uma fantasia individual ${ }^{30}$.

Cabe, enfim, chamar a atenção nesse ponto para a falsa polaridade que se estabeleceu entre a positividade gerada pela "ampliação do imaginário criador e a negatividade decorrente da verticalidade (inibidora) do conhecimento na modernidade. Para os defensores da atitude pós-moderna a imaginação criadora deve voltar-se para a atualidade, ignorando as formalidades e etiquetas da razão ${ }^{31}$. Conforme nota Fredric Jameson (1996), tal perspectiva "crítica" baseia-se numa visão populista ou demagógica 
segundo a qual a cultura do alto modernismo, centrada na razão, teria gerado um valor social estigmatizado por sua associação com a elite universitária, sendo um "passatempo típico do status de um reduzido grupo de intelectuais.

\section{A HOSTILIDADE À TOTALIDADE COMO DISSIMULAÇÃO DO OBSCURANTISMO PÓS-MODERNO}

Observando a postulação "libertária" dos pós-modernistas por um ângulo descompromissado com a totalidade poder-se-ia argumentar, favoravelmente a esta tese, que o que a sua ideologia supostamente reivindica é uma atitude radicalmente "democrática", algo como a supremacia do reino da liberdade (a subjetividade) sobre o da necessidade (o mundo real). Resta saber em que mundo é possível equalizar a liberdade e a necessidade sem que qualquer um dos lados sofresse algum prejuízo?

Três hipóteses possíveis se afiguram.

A primeira, positiva, considera que o discurso relativista do pós-modernismo simplesmente encerra uma utopia legítima de liberdade radical. A segunda, negativa, considera que a negação do que se passa no reino da necessidade é esquizofrênica, não sendo, portanto, válida epistemologicamente. Finalmente, a terceira, observa que ao postular o sabidamente inatingível (a liberdade total, o prazer absoluto, a harmonia perfeita etc.) o que a ideologia pós-moderna reivindica é, na verdade, nada. Ou seja, trata-se de uma forma de cinismo elaborado como um jogo de linguagem numa "grande noite relativista onde todos os gatos são pardos" ( $C f$. LÖWY, 1988). Nesse sentido, sinteticamente, pode-se afirmar que, nos últimos dez anos, o pensamento educacional brasileiro passou a ser hegemonizado por uma epistemologia pós-moderna, ou como define Boaventura de Souza Santos, "mini-racionalidades pós-modernas":

[...] a idéia moderna da racionalidade global da vida social e pessoal acabou por desintegrar numa miríade de miniracionalidades ao serviço de uma irracionalidade global, inabarcável e incontrolável. É possível reinventar as miniracionalidades da vida de modo que elas deixem de ser partes de um todo e passem a ser totalidades presentes em múltiplas partes. É esta a lógica de uma possível pós-modernidade de resistência (2000, p.102).

E mesmo afirmando que as chamadas mini-racionalidades não seriam "racionalidades mínimas", Santos entende que:

A fragmentação maior e mais destrutiva foi-nos legada pela modernidade. A tarefa é agora a de, a partir dela, reconstruir um arquipélago de racionalidades locais, nem mínimas nem máximas, mas tão-só adequadas às necessidades locais, quer existentes quer potenciais, e na medida em que elas forem democraticamente formuladas pelas comunidades interpretativas (p.110.).

Continuando, Boaventura de Souza Santos curiosamente reivindica ainda a posição de socialista: 
As mini-racionalidades pós-modernas estão, pois, conscientes dessa irracionalidade global, mas estão também conscientes que só a podem combater localmente. Quanto mais global for o problema, mais locais e mais multiplamente locais devem ser as soluções. Ao arquipélago destas soluções chamo eu socialismo. São soluções movediças, radicais no seu localismo. Não interessa que sejam portáteis ou mesmo soluções de bolso. Desde que expludam nos bolsos (p.111).

Sem se referir diretamente a Santos, ou a qualquer outro autor em particular, a marxista Ellen Wood, escrevendo em 1995, alerta que a "crítica do capitalismo anda fora de moda":

Os intelectuais de esquerda, quando não abraçam o capitalismo como o melhor dos mundos possíveis, limitam-se a sonhar com pouco mais que um espaço nos seus interstícios e prescrevem apenas resistências locais e particulares (Wood, 2003, p.13).

Para a autora, emerge entre grandes seções da esquerda intelectual uma "hostilidade à totalidade":

O "pós-marxismo" deu lugar ao culto do pós-modernismo, e a seus princípios de contingência, fragmentação e heterogeneidade, sua hostilidade a qualquer noção de totalidade, sistema, estrutura, processo e "grandes narrativas" (Wood, 2003, p.13. Destaques no original).

Enfim, qualquer metanarrativa, seja ela oriunda do positivismo de Comte, da dialética de Hegel ou do materialismo histórico de Marx, foi abandonada pelos apologetas das epistemologias pós-modernas. E com esse abandono, a categoria da totalidade é relegada a um plano bastante secundário, posto que inatingível e mesmo indesejável.

Como já foi indicado mais acima, não só a pesquisa acadêmica no campo educacional vem sendo paulatinamente hegemonizada pelas teorias celebratórias do pósmodernismo, como também a prática pedagógica vem fazendo da escola pública brasileira um laboratório de experiências que prescindem da razão. No limite, ao colocarem a história numa "lata do lixo" proclamam a vitória da "cidadania" no território supostamente autônomo das salas de aula.

Por um percurso bastante distinto, inclusive mantida a referência à totalidade e ao materialismo histórico, em nome da contra-hegemonia, uma parte significativa dos educadores do campo Trabalho-Educação vem cegando o gume crítico de suas pesquisas e de suas interpretações sobre a realidade política e educacional brasileira. Sem o ferrão da crítica, os educadores marxistas ficam desarmados para dar prosseguimento tanto ao combate conjuntural da ofensiva do capital quanto à elaboração de uma pedagogia marxista, obviamente em consonância filosófica e política com uma perspectiva de transformação revolucionária da sociedade. Não por acaso Ellen Wood conclui o seu ensaio sobre as posições políticas "pós-marxistas" assinalando que “[...] um capitalismo 
humano, 'social' e verdadeiramente democrático e igualitário é mais irreal e utópico que o socialismo" (2003, p.250).

Ora, no sentido do que foi exposto aqui sobre o caráter dissimulador do pensamento pós-moderno, o que diz Wood não é apenas pertinente; é, principalmente, exemplar no sentido mesmo daquilo que - tomada a prática social como critério da verdade entendemos ser educativo.

\section{POEIRA NO VENTO: APONTAMENTO SUBSIDIÁRIO PARA REFLETIR SOBRE A CRISE E O FIM DA HEGEMONIA}

Permitindo-nos estender o raciocínio de Ellen Wood para o interior da análise articulada que fizemos da crise do GTTE e do fim da hegemonia marxista no campo educacional, poderíamos concluir que o fim de qualquer coisa que chamamos de educação pública-gratuita-universal-e-democrática e/ou educação profissional-integrada será sempre o de caudatária da democracia formal-burguesa. Em outras palavras, tais concepções jamais alcançariam efetivamente o status contra-hegemônico pois seriam, caso a isso aspirassem, não mais do que um simulacro ou contrafação de tudo aquilo que Marx e Engels denominaram por negação do capitalismo ${ }^{32}$.

Decerto que um raciocínio desse tipo não está isento de possíveis acusações de niilismo e imobilismo seja por parte dos pós-marxistas seja mesmo por parte daqueles que, sinceramente, se creem marxistas. Por outro lado, parece-nos evidente a existência consciente ou não - tanto faz nesse caso - de uma convergência de interesses entre as posições pós-marxistas e a posição marxista que busca "estrategicamente" mediar a luta de classes a fim de nela encontrar uma positividade, ou seja, um "destino". Sobre isso cabe lembrar principalmente aos marxistas que têm compartilhado desta posição que "num mundo governado pela produção de mercadorias, o produto controla o produtor, os objetos têm mais força que os homens. Os objetos tornam-se um "destino", o daemon ex machina" (FISCHER, 1981, p. 96).

Com efeito, se considerado o que o campo educacional conquistou efetivamente ao longo do período sob a política do presidente Lula da Silva veremos que o tal "destino" se apresentou sob a forma de reforço do modelo empresarial de gestão da coisa educacional e, associado à política de Ciência e Tecnologia do mesmo governo ${ }^{33}$, no aumento exponencial do controle sobre o trabalho docente educadores ${ }^{34}$.

Nesse contexto, de forma cada vez mais acentuada, a ANPEd se movimentou tal como um títere operado por fios não tão invisíveis. Isto é, quase sempre em consonância com os desígnios das políticas enunciadas. E não estamos nos referindo apenas a entidade através dos seus dirigentes, mas também aos seus associados institucionais (os Programas de Pós-Graduação em Educação) e individuais (os pesquisadores). De fato, um exame dos documentos e das proposições aprovadas e encaminhadas pelo Fórum dos Programas (FORPRED) e dos trabalhos apresentados nas reuniões da ANPEd no decurso dos últimos seis anos revela a qualidade endógena da entidade e do debate científico que tem promovido, evidenciando a sua fragilidade e o estado de suspensão no qual se encontra. Quanto aos primeiros, os associados institucionais, o muito que se há para analisar documentalmente desde a criação do FORPRED, em 1992, indica a necessidade de um estudo à parte cujo locus não é certamente o deste artigo e cujo espaço aqui não dispomos. Devemos sublinhar, contudo, que o rígido controle exercido pela CAPES através do seu sistema de avaliação tecnomeritocrático não é causal; isto é, não parte desse órgão governamental a atribuição de gerir e controlar os Programas de Pós-Graduação como estes últimos querem fazer parecer. Muito pelo contrário, são precisamente os próprios Programas de Pós-Graduação - leia-se a grande maioria dos professores e pesquisadores 
que neles atuam - que vêm alimentando o sistema de gestão e controle exercido pela CAPES. Já sobre os sócios individuais muito do que dissemos aqui sobre a metamorfose ideológica observada no campo educacional explica a entrega política que fazem da entidade ao controle do demônio ex machina.

A título de conclusão resta saber em que medida o abandono distópico dos pesquisadores tem afetado a pesquisa científica no campo educacional. Mais especificamente buscamos conhecer de que forma a dimensão ética da pesquisa têm sido corrompida por isso no presente, e, a partir daí, nos perguntarmos sobre os desafios se colocam numa perspectiva revolucionária.

Para Florestan Fernandes (1986), tal dimensão se faz necessária para que o pesquisador não desperte "falsas esperanças e crença na transformação automática da sociedade", pois isso apenas "vitalizaria o conservantismo" (pp. 12-49). Em outro escrito, refletindo sobre a autoemancipação dos trabalhadores, ele clama pelo resgate da concepção revolucionária original de Marx e Engels sobre o que deve a classe trabalhadora querer: melhorar as classes, aperfeiçoar a sociedade de classes ou eliminá-las, suprimi-las? (1995, pp. 229-230). Como o "trabalhador não é uma macieira nem a revolução é uma maçã", completa Florestan Fernandes, a história da sociedade de classes engendra ela própria a luta de classes, devendo esta ganhar centralidade pelas mãos da classe trabalhadora. Nesse sentido, vimos no presente trabalho que no decurso de apenas trinta anos, aproximadamente, experimentamos a alegria solar do crescimento de um pensamento de esquerda em educação, original e, até onde a vista alcança, marxista e revolucionário. No mesmo período, porém, experimentamos a tristeza sombria da metamorfose ideológica da esquerda para a direita e o declínio hegemônico do cariz marxista/revolucionário. Nesse processo, nem curto o suficiente para que a memória se apague nem longo necessariamente para que ganhe corpo qualquer coisa além da própria memória, o campo educacional de esquerda e marxista transitou, como diria Florestan Fernandes (1995) entre a prisão das "sucessivas reflexões sobre o marxismo, que vinham prontas e acabadas de fora [...]" e os "contatos tangenciais com a formação da classe operária e o desenvolvimento das lutas sociais dos trabalhadores" (pp. 248-249). Todavia, nesse mesmo processo, pelos fatos e motivações que analisamos ao longo das seções anteriores, os últimos seis anos se mostrariam fora do padrão observado, e, nesse sentido, a emergência de uma quantidade significativa de projetos de pesquisas apoiados em métodos funcionalistas ${ }^{35}$, ecléticos e acríticos, ridiculamente mascarados por um verniz marxista, denota ou evidencia a corrupção da dimensão ética da prática da pesquisa. Não mais se trata de pensar a contribuição da teoria para a revolução nem tampouco, como sublinha Roberto Scharwz (2003), ao "[...] autoesclarecimento da sociedade nacional [para que através dele] se possa superar os preconceitos e tomar conhecimento de sua anatomia e possibilidades reais, podendo então dispor de si" (p.20, grifo do autor). O que temos observado hoje é a pesquisa pela pesquisa movida tão somente pelo "destino" produtivista, cujo "produto científico" em nada contribui para fazer avançar, romper e transformar o conhecimento sobre a realidade.

Enfim, um produto sem acúmulo revolucionário, algo como poeira no vento, em suspensão.

BIBLIOGRAFICA

ALVES, N.; GARCIA, R. L. O sentido da escola. Rio de Janeiro: DP\&A, 1999.

ARONOWITZ, S. Pós-modernismo e política. In: HOLANDA, H. B (Org.). Pósmodernismo e política. Rio de Janeiro: Rocco, 1990,

BONFIM, A. M. Desvendando a área Trabalho e Educação: estudo sobre a produção e 
os produtores do GT de Trabalho e Educação da ANPEd. Rio de Janeiro: Programa de PósGraduação em Educação da PUC - Rio (Tese de doutorado), 2006.

BOTTOMORE, T. (org.). Dicionário do pensamento marxista. Rio de Janeiro: Jorge Zahar, 1983.

CHASIN, J. Marx. Estatuto ontológico e resolução metodológica. São Paulo: Boitempo, 2009.

COHN-BENDIT, D.; GABEIRA, F. Nós que amávamos tanto a revolução. Rio de Janeiro: Rocco, 1985.

CURY, C. R. J. Quadragésimo ano do parecer CFE n 977/65. In Revista Brasileira de Educação, n ${ }^{\circ}$ 30, set/out/nov/dez. Rio de Janeiro/Campinas: ANPEd/ Autores Associados, 2005, pp. 113-118.

DOSSIÊ TRABALHO E EDUCAÇÃO. In Educação em Revista, n³3. Belo Horizonte, MG: 2001, pp. 125-197.

FERNANDES, F. Em busca do socialismo. São Paulo: Xamã, 1995.

A formação política e o trabalho do professor. In CATANI, D. et al. (Orgs.). Universidade, escola e formação de professores. São Paulo: Brasiliense, 1986.

FERRARO, A. R. 2005. A ANPEd, a pós-graduação, a pesquisa e a veiculação da produção intelectual na área de educação. In Revista Brasileira de Educação, ${ }^{\circ}$ 30, set/out/nov/dez. Rio de Janeiro/Campinas: ANPEd/ Autores Associados, 2005, pp. 47-69.

FERREIRA, M. O. L. A crise dos paradigmas e o marxismo entre os pesquisadores em trabalho e educação. In Revista Brasileira de Educação, ${ }^{\circ}$ 21, set/out/nov/dez. Rio de Janeiro/Campinas: ANPEd/ Autores Associados, 2002, pp. 75-89.

FISCHER, E. A necessidade da arte. Rio de Janeiro: Zahar, 1981.

FOUCAULT, M. Microfísica do poder. São Paulo: Graal, 2009.

FRIGOTTO, G. A produtividade da escola improdutiva. Um (re) exame das relações entre educação e estrutura econômico-social capitalista. São Paulo: Cortez/Autores Associados. 1984.

Fazendo pelas mãos a cabeça do trabalhador: o trabalho como elemento pedagógico na formação profissional. In Cadernos de Pesquisa, $n^{\circ}$ 43. São Paulo,1983, pp.38-45.

FRIGOTTO, G.; CIAVATTA, M.; RAMOS, M. A gênese do Decreto n. 5154/2004: um debate no contexto controverso da democracia restrita. In Trabalho Necessário - Revista Eletrônica do Neddate - número 3. Niterói, RJ: Neddate, 2005, www.uff.br/trabalhonecessario.

HANDFAS, A. Uma leitura crítica das pesquisas sobre as mudanças nas condições capitalistas de produção e a educação do trabalhador. Niterói: Programa de PósGraduação em Educação da UFF (Tese de doutorado), 2006.

JAMESON, F. Pós-modernismo: a lógica cultural do capitalismo tardio. São Paulo: Ática, 1996.

KONDER, L. A questão da ideologia. São Paulo: Cia das Letras, 2005.

KUENZER, A. Pedagogia da fábrica: as relações de produção e a educação do trabalhador. São Paulo: Cortez/Autores Associados, 1985.

MEC, 1987.

Educação e trabalho no Brasil: o estado da questão. Brasília: INEP-

Desafios teórico-metodológicos da relação trabalho-educação e o papel social da escola. In: FRIGOTTO, G. (org.). Educação e crise do trabalho: perspectivas de final de século. (5ª ed.). Petrópolis (RJ): Vozes, 2001.

LÖWY, M. As aventuras de Karl Marx contra o barão de Münchhausen: marxismo e 
positivismo na sociologia do conhecimento. (2 ${ }^{\mathrm{a}}$ ed.). São Paulo: Busca Vida, 1988.

MACHADO, L. Politecnia, escola unitária e trabalho. São Paulo: Cortez/Autores Associados, 1989.

MANACORDA, M. A. História da educação: da Antiguidade aos nossos dias. (2 $2^{\mathrm{a}}$ ed.). São Paulo: Cortez/Autores Associados, 1989.

Médicas, 1990.

O princípio educativo em Gramsci. Porto Alegre: Artes Marx e a pedagogia moderna. São Paulo: Cortez/ Autores Associados, 1991.

MARTINS, C. M.; FERREIRA, C. D. ; RODRIGUES, J. O estudo dos processos de trabalho em saúde e a educação politécnica. In: EPSJV (Org.). Formação de pessoal de nível médio para a saúde: desafios e perspectivas. Rio de Janeiro: Editora Fiocruz, 1996. MICELLI, S. Intelectuais à brasileira. São Paulo: Cia. das Letras, 2001.

MIRANDA, K. A organização dos trabalhadores em educação sob a forma-sindicato no capitalismo neoliberal: o pensamento pedagógico e o projeto sindical do SINPRO-Rio, da UPPES e do SEPE-RJ. Niterói: Programa de Pós-Graduação em Educação da UFF, 2005 (Dissertação de Mestrado).

Como os trabalhadores da educação pensam a educação dos trabalhadores: um estudo sobre os sindicatos docentes do Rio de Janeiro. In Anais da 29 ${ }^{\mathbf{a}}$ Reunião Anual da ANPEd. Educação, cultura e conhecimento na contemporaneidade: desafios e compromissos. Caxambu, MG: ANPEd, 2006, www.anped.org.br.

MOTA, C. G. Ideologia da cultura brasileira. São Paulo: Ática, 1978.

NOSELLA, P. Trabalho e perspectivas de formação dos trabalhadores: para além da formação politécnica. In Revista Brasileira de Educação, v.12, n. 34. Rio de Janeiro/Campinas: ANPEd/Autores Associados, 2007, jan./abr, pp.137-151.

REALE, G.; ANTISERI, D. Historia del pensamento filosofico y cientifico. Del romanticismo hasta hoy. Vol. III. Barcelona: Herder, 1988.

REIS, R. R. O abandono da totalidade e a distopia da diversidade. In Revista Conhecimento e Diversidade, $\mathrm{n}^{\circ}$ 3. Niterói, RJ: La Salle, 2010, pp. 65-77.

Pós-modernismo e alienação. In: Anais do VI Colóquio Internacional

Marx-Engels. Campinas, SP: CEMARX - Unicamp, 2009. www.unicamp/cemarx.

Educação e estética. Ensaios críticos sobre arte e formação humana no pósmodernismo. São Paulo: Cortez, 2005a.

Cinema, multiculturalismo e dominação econômica In Crítica Marxista. Campinas/ Rio de Janeiro: CEMARX/Revan, n. 20, 2005b.

. O trabalho da arte e a arte do trabalho. In: FRIGOTTO, G.; CIAVATTA, M.

(Orgs.). A experiência do trabalho e a educação básica. Rio de Janeiro: DP\&A, 2002, pp. 103-116

RODRIGUES, J. (Org.). Dossiê: Sobre o discurso do (des) emprego no governo Lula: cinco estudos sobre a relação entre educação e emprego no discurso do ministro do trabalho. In Trabalho Necessário. Niterói: Neddate - UFF, número 4, 2006a, http://www.uff.br/trabalhonecessario/Jose\%20Rodrigues\%20TN4.htm.

Qual cidadania, qual democracia, qual educação? In Trabalho, Educação e Saúde, v. 4, número 2. Rio de Janeiro: EPJV - Fiocruz, 2006b, pp.417-430.

Ainda a educação politécnica: o novo decreto da educação profissional e

a permanência da dualidade estrutural. In Trabalho, Educação e Saúde, v. 3, número 2. Rio de Janeiro: EPJV - Fiocruz, 2005, pp. 259-282.

A educação e os empresários: o horizonte pedagógico do capital. In:

FRIGOTTO, G.; CIAVATTA, M. (Orgs.). A experiência do trabalho e a educação 
básica. Rio de Janeiro: DP\&A, 2002, pp. 103-116

. A educação politécnica no Brasil. Niterói: EdUFF, 1997.

SANTOS, B. S. Pela mão de Alice. O social e o político na pós-modernidade. São Paulo: Cortez, 2000.

SAVIANI, D. História das idéias pedagógicas no Brasil. Campinas: Autores Associados, 2007 a.

Da nova LDB ao Fundeb: por uma outra política educacional. Campinas: Autores Associados, 2007b.

Trabalho e educação: fundamentos ontológicos e históricos. In Revista

Brasileira de Educação. V.12, n. 34. Rio de Janeiro/Campinas: ANPEd/Autores Associados, 2007c, jan./abr, pp.152-165.

Escola e democracia. (36 ed.). Campinas: Autores Associados, 2003a.

. Pedagogia histórico-crítica: primeiras aproximações. ( $8^{\mathrm{a}}$ ed.). Campinas:

Autores Associados, 2003b.

O choque teórico da politecnia. In Trabalho, Educação e Saúde, vol.1, número 1.

Rio de Janeiro: EPSJV - Fiocruz, 2003c, pp. 131-152.

Educação: do senso comum à consciência filosófica. (14 ed.). Campinas: Autores Associados, 2002.

A nova lei da educação: trajetória, limites e perspectivas. Campinas: Autores Associados, 1997.

Associados, 1996.

Educação brasileira: estrutura e sistema. ( $7^{\mathrm{a}}$ ed.). Campinas: Autores

. Política e educação no Brasil. Campinas: Autores Associados, 1988.

SCHARWZ, R. Prefácio com perguntas. In OLIVEIRA, F. Crítica à razão dualista. $\mathrm{O}$ ornitorrinco. São Paulo: Boitempo, 2003, pp. 12-23.

SGUISSARDI, V.; SILVA Jr. J. R. Trabalho intensificado nas federais. São Paulo: Xamã, 2009.

SHIROMA, E. O.; CAMPOS, R. F. Qualificação e reestruturação produtiva: um balanço das pesquisas em educação. In Educação \& Sociedade. Vol.18, nº.61, dez. 1997, p.13-35.

SILVA Jr., C. A. da (Org.) Dermeval Saviani e a educação brasileira: o simpósio de Marília. São Paulo: Cortez, 1994.

TREIN, E. Entrevista. In Trabalho \& Educação, $n^{\circ}$ 0. Belo Horizonte, MG: NETE UFMG, 1996, pp.32-40.

TREIN, E.; CIAVATTA, M. O percurso teórico e empírico do GT Trabalho e Educação: uma análise para debate. In Revista Brasileira de Educação, $n^{\circ} 24$. Rio de Janeiro/Campinas: ANPEd/Autores Associados, 2003, pp.140-164.

TREIN, E. RODRIGUES, J. O canto de sereia do produtivismo científico: o mal-estar na Academia e o fetichismo do conhecimento-mercadoria. Universidade e Sociedade. ano 20, n.47, fev., 2011, pp.122-132.

TUMOLO, P. S. A produção em "Trabalho e Educação": esboço para discussão de suas marcas e de suas perspectivas. In Trabalho \& Educação, vol. 14, $\mathrm{n}^{\circ}$ 1. Belo Horizonte, MG: NETE - UFMG, 2005, pp.11-22.

WOOD, E. M. Democracia contra capitalismo: a renovação do materialismo histórico. São Paulo: Boitempo, 2003.

YAMAMOTO, O. H. Educação e a tradição marxista: a produção educacional marxista no Brasil dos anos 70/80. São Paulo: Programa de Pós-Graduação em Educação da USP (Tese de Doutorado), 1994.

NOTAS 
${ }^{1}$ Como a da Escola Politécnica de Saúde Joaquim Venâncio, da Fundação Oswaldo Cruz. Cf. MARTINS, FERREIRA e RODRIGUES (1996).

${ }^{2}$ Cf. MIRANDA (2005, 2006).

${ }^{3}$ Diversos trabalhos foram consultados para elaboração desta seção, dentre eles destacamos: BONFIM (2006), Dossiê Trabalho e Educação (2001), FERREIRA (2002); HANDFAS (2006); KUENZER (1987), SHIROMA e CAMPOS (1997); TREIN (1996); TREIN e CIAVATTA (2003); TUMOLO (2005); YAMAMOTO (1994).

${ }^{4}$ José Rodrigues vem participando continuamente do GTTE desde o início dos anos de 1990. Oriundo da área de Arte, Ronaldo Rosas Reis participa do GTTE desde 2001, sendo o seu atual vice-coordenador. Ambos os autores já integraram o Comitê Científico da ANPEd representando o GTTE.

5 A obra de Saviani - bastante marcada pelas obras do pedagogo marxista italiano Mario Alighiero Manacorda (1989, 1990 e 1991) - é vasta, mas podem ser destacados os seguintes livros: Educação brasileira: estrutura e sistema, de 1972 (SAVIANI, 1996); Educação: do senso comum à consciência filosófica, de 1980 (SAVIANI, 2002); Escola de democracia, de 1983 (SAVIANI, 2003a); Política e educação no Brasil, de 1987 (SAVIANI, 1988); Pedagogia histórico-crítica, de 1991 (SAVIANI, 2003b); A nova lei da educação, de 1997 (SAVIANI, 1997); História das idéias pedagógicas no Brasil, de 2007 (SAVIANI, 2007a); Da nova LDB ao Fundeb, de 2007 (SAVIANI, 2007b). Sobre a obra de Saviani, ver SILVA JR. (Org., 1994).

${ }^{6}$ Este aspecto presente na origem da ANPEd é relevante para se compreender a crise atual do campo Trabalho-Educação.

${ }^{7}$ Embora não seja o único ponto de partida, pode-se dizer que tais impulsos alcançaram uma dimensão social pública relevante na década de 1970 com os artigos e palestras de Michel Foucault nos quais ele defendia a idéia de que o poder é uma produção subjetiva sem uma centralidade definida. Reunidos em 1979 numa coletânea de artigos sob o título de Microfísica do poder, os escritos de Foucault tornar-se-iam seminais para as inúmeras tendências do pensamento pós-moderno emergentes na década de 1980 nas ciências sociais aplicadas e nas artes, notadamente na economia, na comunicação, na literatura, no cinema e nas artes plásticas, que passaram a adotá-los de forma conservadora e mesmo reacionária a fim de desconstruir sistematicamente a categoria da Totalidade e atacar a luta de classes como práxis social. Ver FOUCAULT (2009) e para uma abordagem sobre a questão ideológica na sua obra, ver KONDER (2005).

${ }^{8}$ Segundo MOTA (1978), o termo "intelectualidade burguesa de esquerda" é de Roberto Scharwz e foi adotado no ensaio "Nota sobre a vanguarda e o conformismo", em 1967, para criticar as vanguardas intelectuais de origem burguesa. Florestan Fernandes (1995), num dos seus últimos escritos, adota o termo "vanguarda intelectual aburguesada" (p. 249), próximo ao de Scharwz. Para uma leitura historiográfica e crítica do quadro de embates ideológicos da intelectualidade brasileira ver ainda MICELLI (2001).

${ }^{9}$ Uma das marcas importantes do início da caminhada da intelectualidade de esquerda para a diversidade foi, sem dúvida, o livro Nós que amávamos tanto a revolução (1985), de Daniel Cohn-Bendit e Fernando Gabeira, ambos militantes de esquerda nos anos de 1960 e 1970. Ver REIS (2010).

${ }^{10}$ Hoje, Sindicato Nacional dos Docentes das Instituições de Ensino Superior (ANDES-SN).

${ }^{11}$ Foram seis CBEs: 1980, 1982, 1984, 1986, 1988 e 1991.

${ }^{12}$ De cariz produtivista, a concepção tecnicista propõe organizar o processo educativo segundo o modelo do trabalho fabril taylorista-fordista. Na verdade, em seu discurso ideológico, a perspectiva tecnicista reduz toda a complexidade do fenômeno educativo a uma questão "técnica".

${ }^{13}$ No sentido desse comentário, SAVIANI (2003a) distingue três teorias crítico-reprodutivistas: "teoria do sistema de ensino enquanto violência simbólica", de autoria de Bourdieu e Passeron; "teoria da escola enquanto aparelho ideológico de Estado", de Althusser; e a "teoria da escola dualista", de Baudelot e Establet. Para Saviani, se é certo que essas teorias pedagógicas foram importantes para evidenciar os compromissos da educação com os interesses da burguesia, não menos verdadeiro se mostra o caráter imobilista que perpassa cada uma dessas teorias disseminando entre os educadores "um clima de pessimismo e desânimo [...]" (p.33-34).

${ }_{14}^{14} C f$. SAVIANI (2007a, p.418).

${ }^{15}$ Cabe explicitar que concordamos com SAVIANI (2007a, p.417-19 passim) quando este afirma que o grupo-suporte da pedagogia crítico-social dos conteúdos, em que pese sua inspiração marxista, de fato, não superou o horizonte liberal. Com efeito, nos anos 1990, o grupo aderiu explicitamente às reformas neoliberais empreendidas pelo governo do então presidente Fernando Henrique Cardoso (1995-1998; 1999-2002), assumindo inclusive postos nas no poder executivo nas esferas federal, estadual e municipal.

${ }^{16}$ Um aspecto bastante relevante na constituição do GTTE e também na atual crise é a discussão teóricopedagógica sobre a concepção de educação politécnica. Pelas limitações de espaço, sugerimos ao leitor que 
consulte os seguintes textos: RODRIGUES (1997 e 2005), SAVIANI (2003c, 2007b e 2007c) e NOSELLA (2007).

${ }^{17} C f$. TREIN e CIAVATTA (2003, p.145).

${ }^{18}$ Cf. SHIROMA e CAMPOS (1997).

${ }^{19}$ Também não por acaso, o então ministro do trabalho, no governo Lula da Silva, o ex-líder sindical, expresidente da CUT, Luiz Marinho, confirmou esta proposição. Para a íntegra da entrevista (em O Globo, em 06 de março de 2006), já para uma crítica, ver RODRIGUES (Org., 2006a).

${ }^{20}$ Para uma crítica da teoria do capital humano, ver FRIGOTTO (1984).

${ }^{21}$ Ver RODRIGUES (2005).

${ }^{22} \mathrm{O}$ comentário é válido tanto para as áreas das artes, das ciências humanas e das ciências sociais como igualmente para as chamadas ciências "duras". Ver nota 7 mais acima.

${ }^{23}$ No Seminário Choque Teórico, promovido pelo então Politécnico da Saúde Joaquim Venâncio (atual Escola Politécnica de Saúde Joaquim Venâncio), Dermeval Saviani apresentou o texto intitulado Sobre a concepção de politecnia (cf. SAVIANI, 2003c). Ver também RODRIGUES (1997).

${ }^{24}$ Ver RODRIGUES (2005), supramencionado.

${ }^{25}$ O posicionamento deste grupo é representado por FRIGOTTO, CIAVATTA e RAMOS (2005).

${ }^{26}$ Esta é a posição destes autores (Cf. RODRIGUES, 2005 e 2006b).

${ }^{27}$ Cabe explicitar que o conteúdo do decreto 5154/2003 foi integralmente transposto para a LDB (Ver LEI N ${ }^{\circ}$ 11.741, DE 16 DE JULHO DE 2008. Disponível em http://www.planalto.gov.br/ccivil_03/_Ato20072010/2008/Lei/L11741.htm\#art5).

${ }^{28}$ Expressão dessa nova hegemonia é a coleção Sentido da Escola, coordenada por Nilda Alves e Regina Leite Garcia (ALVES e GARCIA, 1999), voltada para um público-leitor formado idealmente por professores da educação básica e estudantes de pedagogia. A referida coleção, editada originariamente pela DP\&A, do Rio de Janeiro, já dispõe de cerca de 30 títulos. Na verdade, a hegemonia da temática do "cotidiano" não é específica do campo educacional, mas vem caracterizando o conjunto das ciências humanas. Cabe talvez explicitar que, em que pese o distanciamento teórico, os autores deste texto participam de um dos volumes da coleção, volume esse organizado no interior do Núcleo de Estudos, Documentação e Dados sobre Trabalho e Educação da Universidade Federal Fluminense (Cf. RODRIGUES, 2002 e REIS, 2002).

${ }^{29}$ A rigor, os "conhecimentos da prática" não passam de uma maldisfarçada forma de retomar o empirismo embutido na perspectiva primária da "prática pela prática".

${ }^{30}$ No plano das políticas culturais, a hostilidade à totalidade dos ideólogos do pós-modernismo traz como contraponto "democrático" o discurso da tolerância para com a diversidade cultural (o multiculturalismo). Sobre este assunto ver REIS (2005b e 2009).

${ }^{31}$ Sobre esse assunto ver REIS (2005a).

${ }^{32}$ Ver o verbete socialismo em BOTTOMORE (org., 1983, p. 339).

${ }^{33}$ Ver TREIN e RODRIGUES (2011).

${ }^{34}$ Sobre o assunto ver MIRANDA (2005 e 2006), anteriormente citada na nota 2, e também SGUISSARDI e SILVA Jr. (2009).

${ }^{35}$ Trata-se o operacionalismo de doutrina neopositivista fundada pelo físico norte-americano P. W. Bridgman cuja principal característica é a recusa da totalidade mediante a redução do significado dos conceitos a uma operação empírica, o que basta para denotar a excentricidade da sua aplicação - ainda que inconsciente ou não deliberada - por parte de quem o faz. Sobre o assunto ver REALE e ANTISERI (1988).

Recebido em: $22 / 11 / 10$

Aprovado em: $20 / 03 / 11$ 